Available online at: http://openjournal.masda.ac.id/index.php/edumasda

Edu Masda Journal

ISSN (Print) 2597-4572 ISSN (Online) 2715-5269

\title{
TINGKAT KEPUASAN PASIEN TERHADAP PELAYANAN KEFARMASIAN DI INSTALASI FARMASI RAWAT JALAN RUMAH SAKIT BHINEKA BAKTI HUSADA
}

\author{
Humaira Fadhilah ${ }^{1 *}$, Nurlita ${ }^{2}$, Ida Listiana ${ }^{3}$
}

${ }^{1,2}$ STIKes Kharisma Persada, Jl. Pajajaran No 1, Tangerang Selatan 15417, Indonesia

${ }^{3}$ STIKes Widya Dharma Husada Tangerang, Jl. Pajajaran No 1, Tangerang Selatan 15417, Indonesia

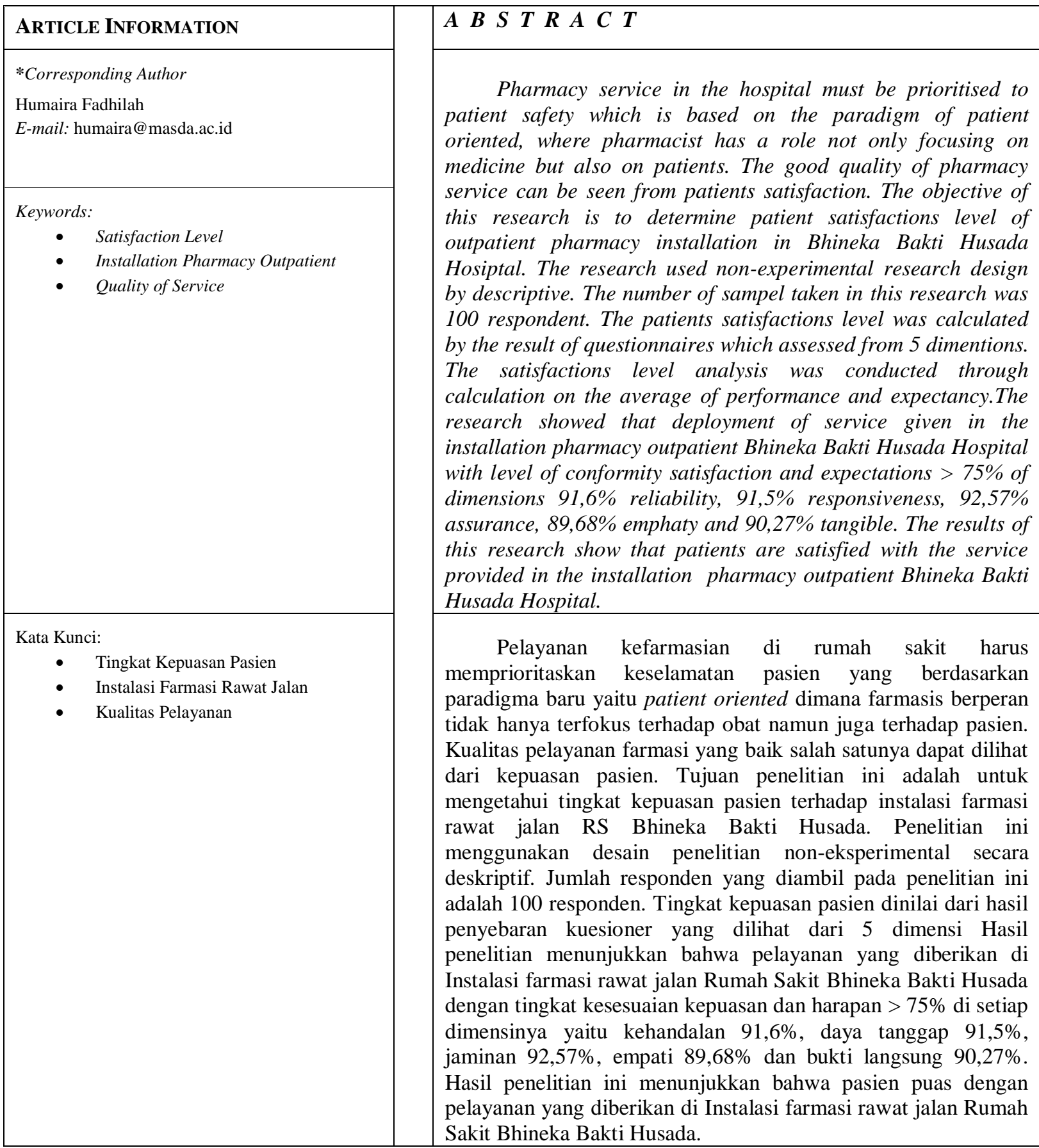




\section{PENDAHULUAN}

Pelayanan kefarmasian di rumah sakit merupakan bagian yang tidak terpisahkan dari sistem pelayanan kesehatan rumah sakit yang berorientasi kepada pelayanan pasien, penyediaan sediaan farmasi, alat kesehatan dan bahan medis habis pakai yang bermutu dan terjangkau bagi semua lapisan masyarakat termasuk pelayanan farmasi klinik. Berdasarkan Peraturan Pemerintah Republik Indonesia Nomor 51 Tahun 2009 tentang pekerjaan kefarmasian menyebutkan bahwa pelayanan kefarmasian adalah suatu pelayanan langsung dan bertanggung jawab kepada pasien yang berkaitan dengan sediaan farmasi dengan maksud mencapai hasil yang pasti untuk meningkatkan mutu kehidupan pasien (Depkes RI, 2009).

Kualitas pelayanan kesehatan adalah pelayanan kesehatan yang dapat menimbulkan kepuasan pada setiap pasien dimana tata cara penyelenggaraannya sesuai dengan standar dan kode etik yang telah ditetapkan. Kepuasan menjadi bagian penting dalam pelayanan kesehatan sebab kepuasan pasien tidak dapat dipisahkan dari kualitas pelayanan kesehatan. Jika ingin melakukan peningkatan kualitas pelayanan maka diperlukan survei tingkat kepuasan pasien. Ada lima dimensi kualitas jasa untuk melihat kepuasan pasien yang dikenal dengan nama SERVQUAL (Service Quality). Kelima dimensi tersebut meliputi, kehandalan (reliability), daya tanggap (responsiveness), jaminan (assurance), empati (emphaty) dan bukti langsung (tangible) (Menurut Parasuraman dalam Daulay, 2015).

Rumah sakit sebagai salah satu institusi pelayanan publik yang dipengaruhi oleh perkembangan ilmu pengetahuan kesehatan, kemajuan teknologi, dan kehidupan sosial ekonomi masyarakat harus mampu meningkatkan pelayanan yang lebih bermutu. Rendahnya suatu mutu pelayanan rumah sakit akan berpengaruh pada ketidakpuasan pasien terhadap mutu pelayanan yang dipengaruhi oleh kualitas pelayanan yang diberikan rumah sakit (Menurut Pohan dalam Putri, 2017).

Kepuasan adalah tingkat perasaan seseorang setelah membandingkan antara kinerja atau hasil yang dirasakan (pelayanan yang diterima dan dirasakan) dengan yang diharapkan (Irene, 2009). Riset Monika, dkk, 2015 telah membuktikan bahwa terdapat hubungan antara pelayanan kefamasian dengan kepuasan pasien. Penelitian yang dilakukan oleh Putri, 2017 menunjukkan 
bahwa secara keseluruhan pasien merasa puas dengan pelayanan farmasi Instalasi farmasi RSUD Cilacap dengan tingkat kesesuaian kinerja dan harapan $>75 \%$.

Penelitian yang dilakukan oleh Tlapana, 2009 bahwa sarana prasarana merupakan salah satu faktor yang dapat mempengaruhi kepuasan pasien. Penelitian yang dilakukan oleh Sulistyawati, dkk 2011, terdapat pengaruh positif antara pemberian informasi obat terhadap kepuasan pasien saat menebus obat. Penelitian yang dilakukan oleh Putu Eka Arimbawa, 2014 bahwa kecepatan pelayanan berhubungan secara signifikan terhadap kepuasan pasien. Penelitian yang dilakukan oleh Manurung, 2010 mengatakan bahwa keramahan petugas memiliki hubungan positif dengan minat kembali menebus resep obat. Hal ini juga didukung oleh penelitian yang dilakukan Saragih, dkk, 2010 yang menyatakan terdapat pengaruh antara keramahan petugas terhadap loyalitas pasien. Pasien yang diperlakukan kurang baik cenderung untuk mengabaikan saran dan nasehat petugas (Yunevy dan Haksamana, 2013).

Ketidakpuasan yang paling sering disampaikan oleh pasien adalah ketidakpuasan terhadap lamanya proses penebusan resep dan peracikan obat, keramahan petugas farmasi. Ketidakpuasan pasien akan berdampak negatif pada kepuasan pasien dan mengakibatkan minat pasien untuk berobat kembali di rumah sakit itu menjadi berkurang, sehingga akan menyebabkan turunnya citra rumah sakit (Rizal, 2014).

Berdasarkan data di atas, maka peneliti tertarik untuk melakukan penelitian dengan judul "Tingkat Kepuasan Pasien Terhadap Pelayanan Kefarmasian Di Instalasi Farmasi Rawat Jalan Rumah Sakit Bhineka Bakti Husada Tahun 2019”.

\section{METODE}

Jenis penelitian yang digunakan adalah penelitian non-eksperimental dengan metode deskriptif. Lokasi penelitian dilakukan di Rumah Sakit Bhineka Bakti Husada selama kurang lebih 2 bulan yaitu bulan April-Mei 2019. Populasi adalah semua pasien atau pendamping pasien rawat jalan di Instalasi Farmasi Rumah Sakit Bhineka Bakti Husada pada bulan April 2019. Sampel penelitian adalah 100 responden yang bersedia mengisi kuesioner. Penelitian ini menggunakan metode non-probability sampling dengan teknik accidental sampling. Teknik pengumpulan data yang dilakukan yaitu dengan menyebarkan kuesioner yang telah divalidasi kepada pasien rawat jalan Instalasi Farmasi 
Rumah Sakit Bhineka Bakti Husada Tahun

2019. Penyebaran kuesioner dilakukan kurang lebih selama 1 minggu pukul 08.00

- 17.00 WIB. Pengolahan data dilakukan dengan menggunakan komputer dengan tahap pengecekan data, pemberian kode, data entry, pembersihan. Analisis data yaitu karakteristik responden, penilaian kuesioner, tingkat kesesuaian.

\section{HASIL}

Tabel 1. Frekuensi Usia

\begin{tabular}{cccc}
\hline No. & Usia & Frekuensi & Persentase \\
\hline 1. & Remaja (12-25 tahun) & 23 & $23 \%$ \\
2. & Dewasa (26-45 tahun) & 41 & $41 \%$ \\
3. & Lansia (46-65 tahun) & 36 & $36 \%$ \\
\hline \multicolumn{2}{c}{ Total } & 100 & $100 \%$
\end{tabular}

Sumber : (Data Primer, 2019)

Berdasarkan tabel 1, hasil

paling banyak pada usia dewasa penelitian menunjukkan bahwa frekwensi responden menurut usia (26-45 tahun) dengan persentase sebesar $41 \%$.

Tabel 2. Frekuensi Jenis Kelamin

\begin{tabular}{rlcc}
\hline No. & Jenis Kelamin & Frekuensi & Persentase \\
\hline 1. & Perempuan & 73 & $73 \%$ \\
2. & Laki-laki & 27 & $27 \%$ \\
\hline & Total & 100 & $100 \%$ \\
\hline
\end{tabular}

Sumber : (Data Primer, 2019)

Berdasarkan tabel 2 dapat dilihat dari penyebaran kuesioner kepada

100 responden bahwa pasien yang menebus obat di Instalasi farmasi rawat jalan Rumah Sakit Bhineka
Bakti Husada sebagian besar berjenis kelamin perempuan dengan persentase sebesar $73 \%$ sedangkan untuk pasien laki-laki sebesar $27 \%$.

Tabel 3. Frekuensi Pendidikan

\begin{tabular}{clcc}
\hline No. & Pendidikan & Frekuensi & Persentase \\
\hline 1. & SD/Sederajat & 5 & $5 \%$ \\
2. & SMP/Sederajat & 11 & $11 \%$ \\
3. & SMA/Sederajat & 53 & $53 \%$ \\
\hline
\end{tabular}




\begin{tabular}{clcc}
\hline No. & \multicolumn{1}{c}{ Pendidikan } & Frekuensi & Persentase \\
\hline 4. & Akademi/Diploma & 12 & $12 \%$ \\
5. & S1 & 17 & $17 \%$ \\
6. & Lainnya & 2 & $2 \%$ \\
\hline & Total & 100 & $100 \%$
\end{tabular}

Sumber : (Data Primer, 2019)

Pada tabel 3 menunjukkan

karakteristik responden berdasarkan

pendidikan terakhirnya. Dari hasil

penelitian, pendidikan terakhir responden yang paling banyak adalah pendidikan menengah ke atas (SMA/Sederajat) dengan nilai persentase sebesar 53\%.

\section{Tabel 4 Frekuensi Pekerjaan}

\begin{tabular}{cccc}
\hline No. & Pekerjaan & Frekuensi & Persentase \\
\hline 1. & Pegawai/Karyawan Swasta & 22 & $22 \%$ \\
2. & PNS/POLRI/TNI & 3 & $3 \%$ \\
3. & Wiraswasta & 13 & $13 \%$ \\
4. & Lainnya & 62 & $62 \%$ \\
\hline \multicolumn{2}{c}{ Total } & 100 & $100 \%$ \\
\hline
\end{tabular}

Sumber : (Data Primer, 2019)

Berdasarkan tabel 4 dapat dilihat

bahwa responden pada penelitian

ini yang mempunyai persentase

paling besar adalah kelompok lainnya dengan persentase sebesar $62 \%$, kelompok lainnya ini sebagian besar merupakan pasien pensiunan serta ibu rumah tangga

Tabel 5 Kepuasan Tiap Dimensi

\begin{tabular}{lcccc}
\hline \multicolumn{1}{c}{ Dimensi } & $\begin{array}{c}\text { Rata- rata } \\
\text { kepuasan }\end{array}$ & $\begin{array}{c}\text { Rata- rata } \\
\text { harapan }\end{array}$ & $\begin{array}{c}\text { Tingkat } \\
\text { Kesesuaian }\end{array}$ & $\begin{array}{c}\text { Tingkat } \\
\text { Kepuasan }\end{array}$ \\
\hline $\begin{array}{l}\text { Kehandalan } \\
\text { (Reliability) }\end{array}$ & 18,32 & 20 & $91,6 \%$ & Puas \\
$\begin{array}{l}\text { Daya Tanggap } \\
\text { (Responsivenes) }\end{array}$ & 24,04 & 26,26 & $91,5 \%$ & Puas \\
$\begin{array}{l}\text { Jaminan } \\
\text { (Assurance) }\end{array}$ & 24,33 & 26,28 & $92,57 \%$ & Puas \\
$\begin{array}{l}\text { Empati } \\
\text { (Emphaty) }\end{array}$ & 17,30 & 19,29 & $89,68 \%$ & Puas \\
$\begin{array}{l}\text { Bukti } \\
\text { Langsung } \\
\text { (Tangible) }\end{array}$ & 24,23 & 26,84 & $90,27 \%$ & Puas \\
\hline Sumber: (Data Prim & & & &
\end{tabular}

Sumber : (Data Primer, 2019) 
Dari hasil perhitungan tingkat kesesuaian dapat dilihat bahwa pasien menyatakan puas terhadap pelayanan kefarmasian di Instalasi farmasi rawat jalan Rumah Sakit Bhineka Bakti Husada, dengan nilai tingkat kesesuaian antara kepuasan dan harapan $>75 \%$ pada tiap dimensinya.

\section{PEMBAHASAN}

Hasil dari penelitian menunjukkan bahwa pasien yang menjadi responden penelitian sebagian besar berusia dewasa yaitu kisaran 26- 45 tahun dengan persentase sebesar $41 \%$. Bertambahnya usia seseorang dapat berpengaruh pada kesehatannya, dimana terjadi kemunduran struktur dan fungsi organ, sehingga masyarakat yang berusia lebih tua lebih cenderung banyak memanfaatkan pelayanan kesehatan dibandingkan dengan usia muda (Menurut Gunarsa dalam Urrahmah, 2018).

Dari hasil penelitian dengan jumlah responden sebanyak 100 orang diperoleh persentase responden berjenis kelamin perempuan sebesar $73 \%$ dan responden berjenis kelamin laki-laki sebesar 27\% sehingga dapat dinyatakan responden perempuan lebih banyak daripada responden laki-laki. Jenis kelamin merupakan salah satu faktor yang dapat mempengaruhi individu dalam menyikapi suatu produk atau jasa pelayanan (Menurut Kotler dalam Urrahmah, 2018). Tingkat harapan kepuasan responden terbilang tinggi meskipun sebagian besar berjenis kelamin perempuan. Hal ini disebabkan karena lebih banyak pasien perempuan yang bersedia menjadi responden dalam penelitian ini.

Hasil penelitian menunjukkan bahwa pendidikan terakhir responden sebagian besar adalah tamat SMA/Sederajat dengan persentase sebesar 53\%. Berdasarkan dari hasil penelitian yang dilakukan, tingkat pendidikan responden terbanyak yaitu tingkat menengah ke atas (SMA/Sederajat), maka dapat peneliti simpulkan bahwa tingkat harapan kepuasan responden terbilang tinggi. Hal ini disebabkan karena pasien pada Instalasi farmasi rawat jalan Rumah Sakit Bhineka Bakti Husada memiliki tingkat pendidikan yang sedang sehingga pasien cenderung merasa puas dengan pelayanan yang diberikan oleh petugas farmasi.

Hasil penelitian yang didapat menunjukkan bahwa pekerjaan responden yang paling banyak yaitu kelompok lainnya dengan persentase sebesar $62 \%$, kelompok lainnya ini sebagian besar merupakan pasien pensiunan dan ibu 
rumah tangga. Pekerjaan mempengaruhi tingkat kepuasan pasien terhadap pelayanan kesehatan yang diterimanya karena orang yang bekerja lebih tinggi harapannya dibandingkan dengan yang tidak bekerja. Pekerjaan ada hubungannya dengan penghasilan seseorang untuk berprilaku dalam menentukan pelayanan yang diinginkan. Seseorang yang memiliki pekerjaan yang lebih tinggi memiliki harapan yang tinggi khususnya pada sarana dan prasarana farmasi (Anggraini, 2014).

Berdasarkan dari hasil penelitian yang dilakukan, dimana tingkat pekerjaan responden terbanyak yaitu kelompok lainnya yang sebagian besar merupakan pasien pensiunan dan ibu rumah tangga, dari hal tersebut dapat peneliti simpulkan bahwa tingkat harapan kepuasan responden terbilang tinggi meskipun responden tidak bekerja. Hal tersebut disebabkan pasien yang tidak bekerja memiliki banyak waktu untuk melakukan pengobatan sehingga pasien cenderung mudah menerima dan merasa puas terhadap pelayanan farmasi yang diberikan.

Dimensi kehandalan (reliability) rata-rata kepuasan yang diperoleh lebih rendah dibandingkan dengan rata-rata harapan responden, hal ini disebabkan oleh jumlah petugas farmasi yang terbatas dan harus melayani banyak pasien yang menebus obat di instalasi farmasi rawat jalan terlalu banyak sehingga petugas farmasi tidak dapat memberikan pelayanan yang maksimal kepada pasien. Namun secara keseluruhan berdasarkan tingkat kesesuaian antara kepuasan dan harapan yang diperoleh $\geq 75 \%$ yaitu sebesar $91,6 \%$ dapat dinyatakan responden puas dengan pelayanan farmasi pada dimensi kehandalan (reliability).

$$
\text { Dimensi daya tanggap }
$$

(responsiveness) menunjukkan rata-rata kepuasan yang lebih rendah dibandingkan dengan rata-rata harapan. Hal ini terjadi karena terdapat nilai kepuasan yang paling rendah dari 8 pertanyaan pada kuesioner yaitu 2,86 pada pertanyaan nomor 1 . Pertanyaan tersebut mengenai apakah obat diberikan tepat waktu oleh petugas farmasi, berdasarkan jawaban kuesioner dapat dilihat bahwa terdapat banyak responden yang menjawab tidak setuju bahkan sangat tidak setuju, hal ini karena pasien harus menunggu antrean yang sangat lama. Dimensi daya tanggap (responsiveness) secara keseluruhan berdasarkan tingkat kesesuaian antara kepuasan dan harapan yang diperoleh $\geq$ $75 \%$ yaitu sebesar $91,5 \%$ dapat dinyatakan responden puas tetapi dengan rata-rata kepuasan yang lebih rendah dibandingkan dengan rata-rata harapan responden. Hal 
ini disebabkan oleh antrean pasien yang ingin menebus obat di instalasi farmasi rawat jalan terlalu banyak sehingga petugas farmasi membutuhkan waktu untuk menyiapkan obat dan dibutuhkan ketelitian dalam mengerjakannya.

Dimensi jaminan (assurance) menunjukkan rata-rata kepuasan yang lebih rendah dibandingkan dengan rata-rata harapan. Hal ini terjadi karena terdapat nilai kepuasan yang paling rendah dari 8 pertanyaan pada kuesioner yaitu 2,60 pada pertanyaan nomor 5. Pertanyaan tersebut yaitu apakah layanan yang diberikan cepat dan tepat, sebagian besar responden menjawab tidak setuju karena pasien harus menunggu lama untuk mendapatkan obat. Dimensi jaminan (assurance) rata-rata kepuasan yang diperoleh lebih rendah dibandingkan dengan rata-rata harapan responden. Hal ini disebabkan oleh banyaknya resep yang harus dikerjakan oleh petugas farmasi dan terbatasnya jumlah petugas farmasi sehingga pasien membutuhkan waktu yang cukup lama untuk mendapatkan obat. Namun secara keseluruhan berdasarkan tingkat kesesuaian antara kepuasan dan harapan yang diperoleh lebih $\geq 75 \%$ yaitu sebesar 92,57\% dapat dinyatakan responden puas terhadap pelayanan farmasi pada dimensi jaminan (assurance).
Dimensi empati (emphaty) menunjukkan rata-rata kepuasan yang lebih rendah dibandingkan dengan rata-rata harapan. Hal ini terjadi karena terdapat nilai kepuasan yang paling rendah dari 6 pertanyaan yaitu 2,65 pada pertanyaan nomor 2. Pertanyaan tersebut mengenai apakah petugas farmasi memantau keluhan pasien tentang pengobatan. Dimensi empati (emphaty) secara keseluruhan masuk dalam kategori puas tetapi rata-rata kepuasan yang diperoleh lebih rendah daripada rata-rata harapan responden. Hal ini disebabkan oleh jumlah pasien yang datang ke Instalasi farmasi rawat jalan terlalu banyak sehingga petugas farmasi tidak dapat memantau satu persatu keluhan pasien tentang pengobatan.

Dimensi bukti langsung (tangible) menunjukkan rata-rata kepuasan yang lebih rendah dibandingkan dengan rata-rata harapan. Hal ini terjadi karena terdapat nilai kepuasan yang paling rendah dari 8 pertanyaan yaitu 2,41 pada pertanyaan nomor 8. Pertanyaan tersebut mengenai apakah obat yang terdapat dalam resep selalu tersedia di instalasi farmasi rumah sakit, sebagian besar responden tidak setuju bahkan sangat tidak setuju dengan pertanyaan tersebut. Dimensi bukti langsung (tangible) rata-rata kepuasan yang diperoleh lebih rendah dibandingkan 
dengan rata-rata harapan responden. Hal ini disebabkan sebagian besar responden adalah pasien BPJS sehingga obat yang diberikan oleh petugas farmasi hanya sebagian saja dan ada obat-obat yang tidak ditanggung oleh BPJS sehingga pasien harus membayar. Namun secara keseluruhan berdasarkan tingkat kesesuaian antara kepuasan dan harapan pasien yang diperoleh lebih $\geq 75 \%$ yaitu sebesar 90,27\% dapat dinyatakan responden puas dengan pelayanan farmasi pada dimensi bukti langsung (tangible).

\section{KESIMPULAN}

Berdasarkan hasil penelitian mengenai tingkat kepuasan pasien pada pelayanan kefarmasian di Instalasi farmasi rawat jalan Rumah Sakit Bhineka Bakti Husada Tahun 2019 dapat disimpulkan sebagai berikut : usia responden adalah usia dewasa (26-45 tahun) 41\%, Jenis Kelamin perempuan $73 \%$, Pendidikan SMA/Sederajat 53\%, Pekerjaan pensiunan dan ibu rumah tangga $62 \%$. Pasien menyatakan puas terhadap pelayanan kefarmasian di Instalasi farmasi rawat jalan Rumah Sakit Bhineka Bakti Husada, dengan nilai tingkat kesesuaian antara kepuasan dan harapan $>75 \%$ pada tiap dimensinya.

\section{DAFTAR PUSTAKA}

Anggraini S., Lia dan Kirana Nathalia. 2014. Desain Komunikasi Visual ; Dasar-Dasar Panduan Untuk Pemula. Bandung: Nuansa Cendekia

Arikunto, S. 2009. Prosedur Penelitian Suatu Pendekatan Praktik. Jakarta: Rineka Cipta

Bertawati. 2013. Profil pelayanan kefarmasian dan kepuasan konsumen apotik di Kecamatan Adiwerna Kota Tegal. Jurnal Ilmiah Mahasiswa Universitas Surabaya.

Daulay, M.A. 2015. Tingkat kepuasan pasien rawat jalan peserta BPJS kesehatan terhadap pelayanan kefarmasian di dua puskesmas di Kota Medan. Skripsi, Fakultas Farmasi, Universitas Sumatera Utara.

Irene, D.S, 2009. Manajemen Pemasaran Usaha Kesehatan. Yogyakarta: Nuha Medika

Kurniati. 2013. Kepuasan Pasien Rawat Inap Lontara Kelas III Terhadap Pelayanan Kesehatan Di Rumah Sakit Wahidin Sudirohusodo. Makassar: Universitas Hasanuddin

Manurung, L. 2010. Analisis Hubungan Tingkat Kepuasan Pasien Rawat 
Jalan Terhadap Pelayanan Instalasi Farmasi Dengan Minat Pasien Menebus Kembali Resep Obat di Instalasi Farmasi RSUD. Budhi Asih 2010. Tesis. Jakarta: Universitas Indonesia

Monika, K. 2015. Hubungan antara Mutu Pelayanan Kefarmasian Dengan Kepuasan Pasien Rawat Jalan di Puskesmas Teling Atas Kota Manado. Jurnal Ilmiah Farmasi. UNSRAT. Volume 4 No.4

Notoatmodjo, S. 2010. Metodologi Penelitian Kesehatan. Jakarta: Rineka Cipta

Notoatmodjo, S. 2012. Metodologi Penelitian Kesehatan. Jakarta: Rineka Cipta

Nursalam., Efendi, F. 2011. Pendidikan dalam Keperawatan. Jakarta: Salemba Medika

Permatasari, Linda. 2016. Analisis Kepuasan Pasien Terhadap Kualitas Pelayanan Farmasi Rawat Jalan Di Rumah Sakit Umum Daerah Singaparna Medika Citrautama Kabupaten Tasikmalaya. Yogyakarta : Universitas Muhammadiyah Yogyakarta
Putri, N. 2017. Analisis Tingkat Kepuasan Pasien Terhadap Pelayanan Farmasi Di Instalasi Farmasi Satelit Rawat Jalan Rumah Sakit Umum Daerah Cilacap. Skripsi. Yogyakarta: Universitas Muhammadiyah Yogyakarta

Rizal, M. 2014. Analisis Tingkat Kepuasan Pasien Terhadap Pelayanan Di Instalasi Farmasi Rumah Sakit PKU Muhammadiyah Bantul Periode JuliSeptember 2013. Skripsi. Yogyakarta: Universitas Muhammadiyah Yogyakarta

Saragih, L., dkk. 2010. Pengaruh Mutu Pelayanan Kesehatan Terhadap Loyalitas Pasien Rumah Sakit Umum Herna Medan. Tesis. Medan: Universitas Sumatera Utara

Sugiyono. 2012. Metode Penelitian Administrasi Cetakan Ke-20. Bandung: Alfabeta

Sulistyawati, M., dkk. 2011. Hubungan Kualitas Pelayanan Farmasi Pasien Rawat Jalan Terhadap Kepuasan Dan Keputusan Membeli Ulang Obat Di IFRS Jala Ammari. Makassar

Tlapana, T.P. 2009. Store Layout And Its Impact On Consumer Purchasing Behavior At Convenience In Kwa 
Mashu. Disertasi, Durban University

Of Technology

Urrahmah, Syifa. 2018. Tingkat Kepuasan

Pasien Tehadap Pelayanan

Komunikasi, Informasi dan Edukasi

(KIE) Obat oleh Petugas Farmasi di Instalasi Farmasi Rumah Sakit

Umum Kota Tangerang. Tangerang:

STIKes Kharisma Persada

Yunevy, E dan Haksama, S. 2013. Analisis

Kepuasan Berdasarkan Persepsi Dan

Harapan Pasien Di Puskesmas

Medokan Ayu Surabaya. Jurnal
Administrasi Kesehatan Indonesia.

Surabaya

Yuniar, Yuyun. 2016. Kepuasan Pasien Peserta Program Jaminan Kesehatan Nasional Terhadap Pelayanan Kefarmasian di Apotek. Jurnal Kefarmasian Indonesia 

